\title{
Malignant melanoma of the choroid in a mother and retinoblastoma in her son
}

\author{
SEIJI HAYASAKA AND KATSUYOSHI MIZUNO \\ From the Department of Ophthalmology, Tohoku University School of Medicine, Sendai, Japan
}

SUMMARY A 31-year-old woman was diagnosed as having a malignant melanoma of the choroid in the right eye. Twenty months later her 7-year-old son was diagnosed as having retinoblastoma in the right eye. Both diagnoses were confirmed histopathologically after enucleation. A chromosomal study revealed normal karyotypes in the son. The family history was positive for cancer of the stomach. The implications of this rare association are discussed.

Cancers have been noted to occur with high frequency among blood relatives. ${ }^{2}$ The hereditary aspects of retinoblastoma in particular have been reported in relatives of affected children. ${ }^{2-4}$ Retinoblastoma is rarely found in patients after the age of $7,,^{56}$ and uveal malignant melanoma is also uncommon in the Japanese population. ${ }^{7}$ We describe a rare malignant melanoma of the choroid in a mother and retinoblastoma in her 7-year-old son in a pedigree with a hereditary tendency to stomach cancer.

\section{Family and case reports}

The family tree (Fig. 1) shows a hereditary tendency to stomach cancer in this pedigree: cases I-4, I-6, II-1,

Correspondence to Seiji Hayasaka, MD, Department of Ophthalmology, Tohoku University School of Medicine, Sendai, Japan.
II-6, II-13, and III-2 died of stomach cancer. Case II-5 died of oesophageal cancer. Case III-3 died of carcinoma of the corporis uteri. Cases I-1, I-2, I-5, and II-4 possibly died from cerebral apoplexy. Case I-3 died of puerperal fever. Cases II-2, II-3, II-7, and III-1 died early in life, but their medical records were not available. Case II-12 was under examination for possible stomach cancer.

CASE III-I 4 (PROBAND)

A 31-year-old woman noticed blurred vision in her right eye on 30 December 1982. The next day she was referred to Tohoku University Hospital. Her past medical history was non-contributory. Her best corrected vision was $0.6 \mathrm{OD}$ and $1.2 \mathrm{OS}$. The intraocular pressure was $12 \mathrm{mmHg}$ OU. The eye positions and movements were normal. The cornea, anterior chamber, and lens were transparent bilaterally. Her irides were brown, with no heterochromia. Ophthalmoscopically a tumour 7 disc diameters long

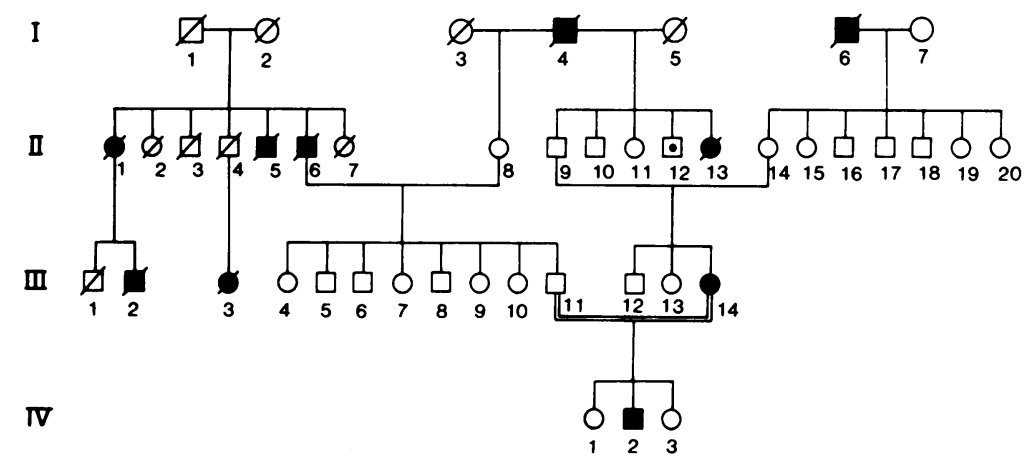

Fig. 1 The family tree. $\square$ male; female; male with malignant neoplasm; female with malignant neoplasm; $\square$ male suspected of malignant neoplasm; / =died; =consanguineous marriage. 


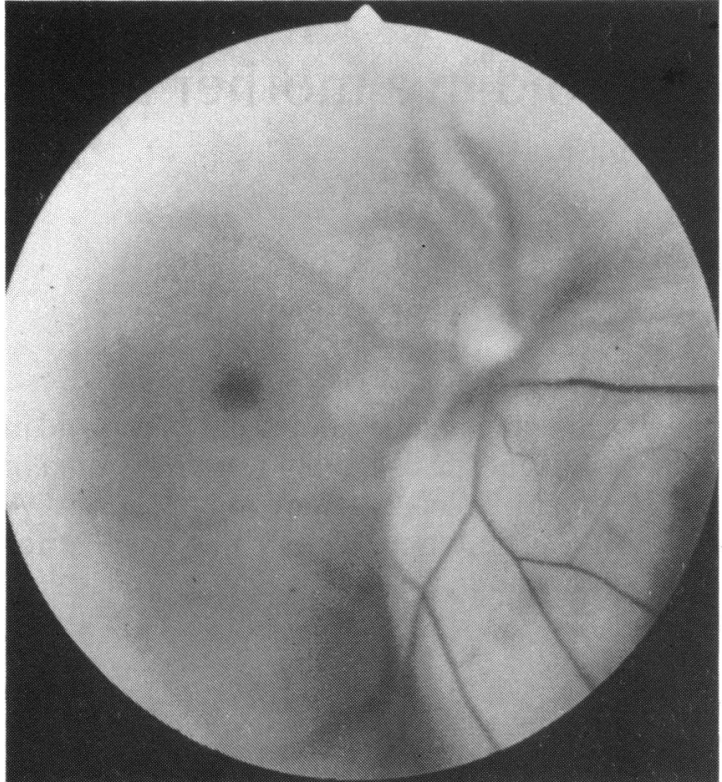

Fig. 2 Fundus photograph of the proband (case III-14). Pigmented tumorous mass is visible inferonasally in the right fundus.

and 5 dioptres deep was found inferonasally in the right eye. Spotted pigmentation was noted under the surface of mass (Fig. 2). The clinical impression of malignant melanoma was supported by fluorescein angiography, orbital computed tomography, and ultrasonography. Systemic examination and laboratory studies were negative for extraocular melanoma.

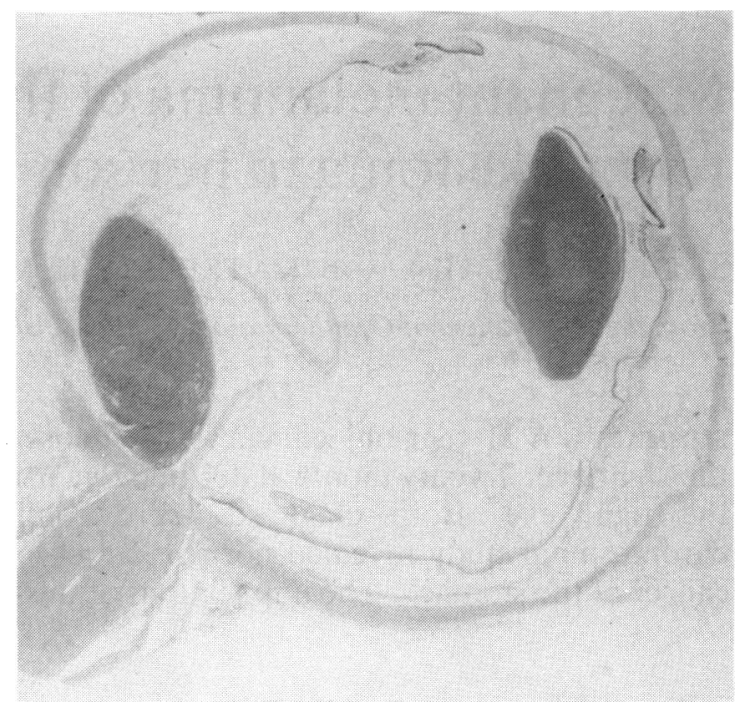

Fig. 3a Histopathological specimen from the right eye of the proband. Pigmented mass is visible near the optic disc. ( $H$ and $E, \times 3$ ).

Late in January a secondary retinal detachment extended to the macular area, and visual acuity in the right eye decreased to $0 \cdot 05$. On 1 February 1983 the right eye was enucleated. Pathological examination showed a malignant melanoma of the choroid, predominantly composed of spindle B cells, without scleral or extraocular invasion (Figs. 3a, b). In March 1985 the patient was alive and well with no evidence of metastatic disease.
Fig. 3b Histopathological specimen from the right eye of the proband. High magnification shows spindle B melanoma cells. (Hand $E, \times 150$ ).

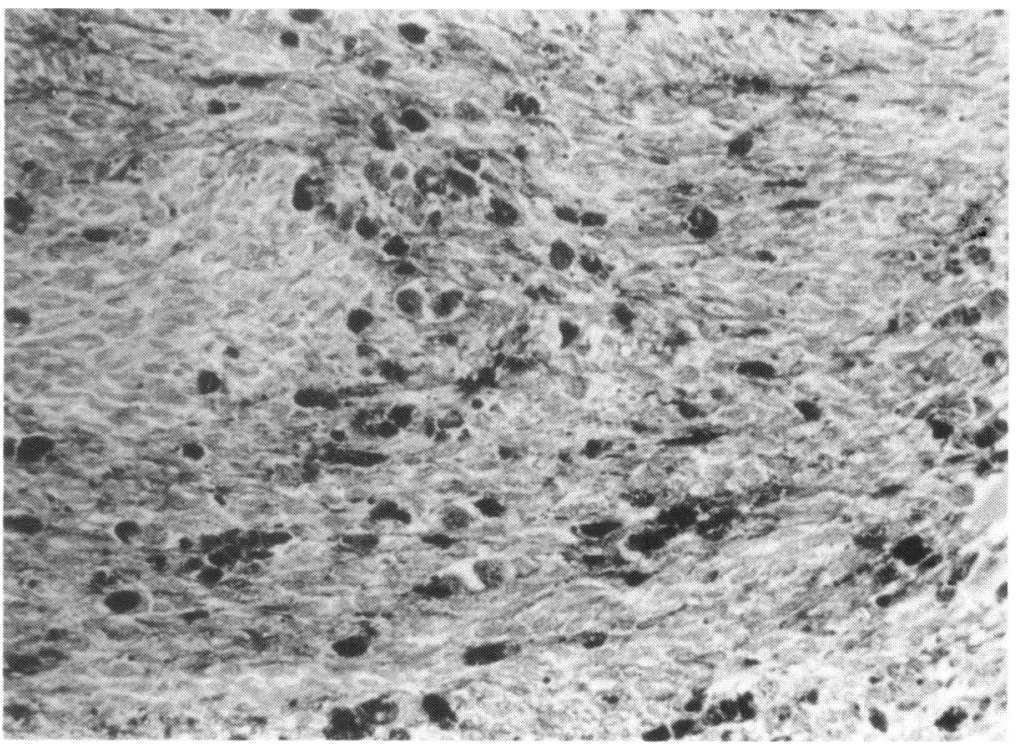




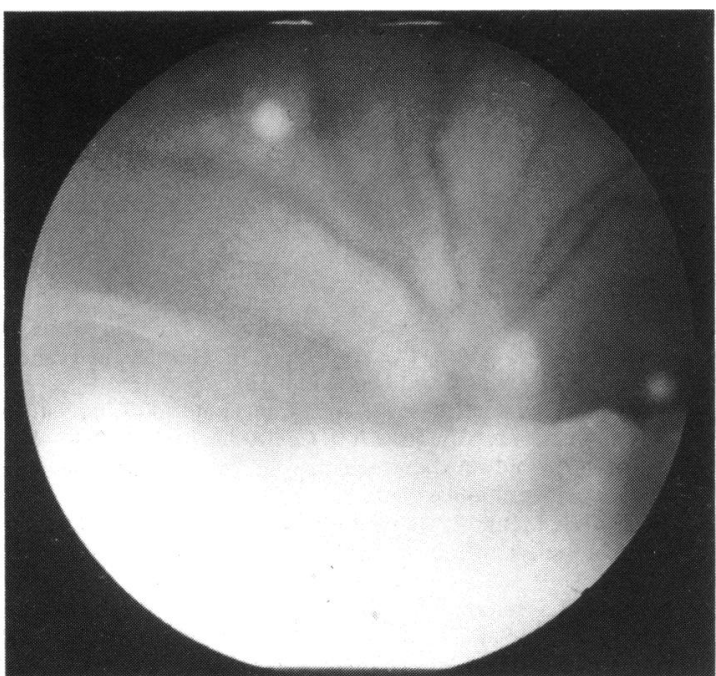

Fig. 4 Fundus photograph of the proband's son (case IV-2) shows a yellowish-white mass, retinal detachment, and floating clusters.

CASE IV-2 (SON OF PROBAND)

The boy's parents were consaguineous. Because of his mother's condition the child was examined by indirect ophthalmoscopy in January 1983 at the age of 6 years. His fundi appeared normal. On 22 March 1984 his right eye was struck with a pencil at school. His corrected vision was 1.0 OU. A slit-lamp examination disclosed a small conjunctival laceration, which healed two weeks later. An ophthalmoscopic examination showed no haemorrhage, oedema, or tumour in the right fundus.

On 1 September 1984, at the age of 7, he returned to us with a white pupil. His visual acuity was hand motions $O D$ and 1.0 with myopic correction $(-0.25 \mathrm{D})$ OS. The intraocular pressure was 12 $\mathrm{mmHg}$ OD and $15 \mathrm{mmHg}$ OS. The cornea, anterior chamber, and lens were clear bilaterally. Ophthalmoscopically a yellowish-white mass 6 disc diameters in length and 4 dioptres in depth and a retinal detachment were seen inferiorly in the right eye (Fig. 4). Neovascularisation was noted under the surface of the mass, but pigmentation was not found. Several small whitish clusters floated in the posterior vitreous. A single bright-flash ERG response was subnormal in the right eye and normal in the left. The clinical impression of retinoblastoma was supported by ultrasonography and orbital computed tomography. Systemic evaluation and laboratory studies were negative for extraocular extension. A chromosomal analysis revealed normal karyotypes. On 11 September 1984 the involved right eye was enucleated. An increased level of lactic dehydro-

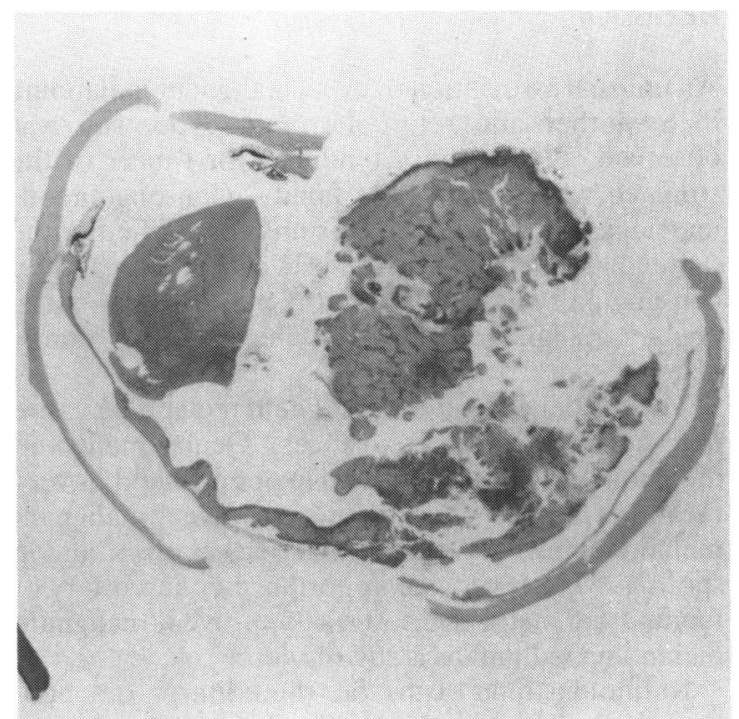

Fig. 5a

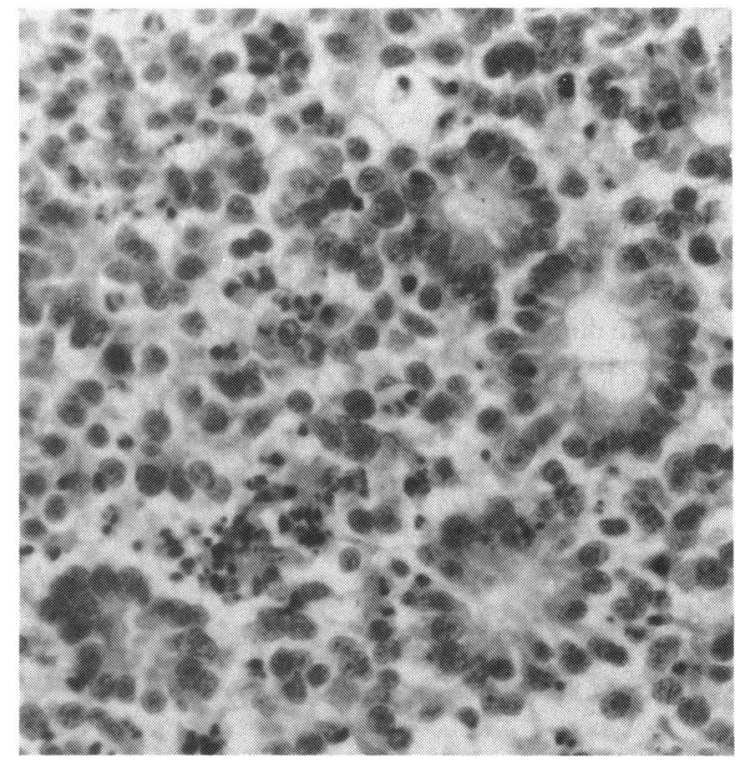

Fig. 5b

Fig. 5 Histopathological specimen from the right eye of the proband's son. (a) Tumorous mass extends into the vitreous cavity. (H and $E, \times 3)$. (b) Flexner-Wintersteiner rosettes are visible. (H and $E, \times 250)$.

genase activity was found in the aqueous humour. Pathological examination showed a retinoblastoma composed of rosette formations without extraocular extension of the tumour (Figs. 5a, b). In March 1985 the patient was alive and well with no evidence of metastatic disease. 


\section{Discussion}

An unusual association of uveal malignant melanoma in a mother and retinoblastoma in her son was observed. A hereditary tendency for cancer of the stomach was noted in the family. Consanguineous marriage was also found. It is unknown whether the familial occurrence of stomach cancer or parental consanguinity was related to the pathogenesis of the ocular malignancy, despite the positive family history. ${ }^{4}$

The incidence of uveal malignant melanoma varies markedly among different races. ${ }^{8}$ Ocular malignant melanoma, such as that found in our proband, is very rare in Japan. ${ }^{7}$ Only a few cases of uveal malignant melanoma have developed in blood relatives ${ }^{9}$ and in spouses. ${ }^{10}$ However, the importance of hereditary or familial factors in the aertiology of uveal malignant melanoma in humans is still obscure.

Retinoblastoma can be hereditary or nonhereditary. The hereditary form is found in all cases of bilateral retinoblastoma and in a small group of unilateral cases. " Chromosome 13 deletion has been reported in some patients with familial retinoblastoma. ${ }^{12}$ Our case IV-2 (son) had unilateral retinoblastoma and normal chromosomal findings, suggesting a non-hereditary form of the disease. His intraocular tumor was discovered at the age of 7 years. Five months before this his fundi appeared normal ophthalmoscopically, pointing to the rapid growth of the retinoblastoma.

Death due to melanoma in two relatives of patients with bilateral retinoblastoma has been reported in one family. ${ }^{2}$ However, we have no apparent explanation for the rare occurrence of the two different neoplasms in our family. Electron microscopy failed to reveal viral particles in the tumours in our cases, and chromosomal analysis showed normal findings. Perhaps other such cases reported in future may reveal common aetiological factors.

The authors thank Dr T Yamada for preparing the figures, and Ms M Gere for editing the manuscript.

\section{References}

1 Knudson AG Jr, Strong LC, Anderson DE. Heredity and cancer in man. Prog Med Genet 1978; 9: 113-58.

2 Strong LC, Herson J, Haas C, et al. Cancer mortality in relatives of retinoblastoma patients. $J$ Natl Cancer Inst 1984; 73: 303-11.

3 Fedrick J, Baldwin JA. Incidence of cancer in relatives of children with retinoblastoma. $\mathrm{Br}$ Med J 1978; i: 83-4.

4 Whelan H, Mehta P. Association of retinoblastoma and acute lymphoblastic leukemia in a family. Am J Pediatr Hematol Oncol 1982; 4: 37-9.

5 Francois J. Heredity of malignant tumours of the eye. In: Symposium on Surgical and Medical Management of Congenital Anomalies of the Eye. Trans New Orleans Acad Ophthalmol 1968: 199-246.

6 Watanabe K. Clinical study of malignant tumors in Osaka University over a twenty-year period. Folia Ophthalmol Jpn 1984; 35: 2201-6.

7 Kaneko A. Incidence of malignant melanoma of the eye in Japan, 1972-1976. Jpn J Clin Ophthalmol 1979; 33: 941-7.

8 Hogan MJ, Zimmerman LE. Tumours of the uveal tract. Ophthalmic pathology, an atlas and textbook, 2nd ed. Philadelphia: Saunders, 1962: 413-60.

9 Lynch HT, Anderson DE, Krush AJ. Heredity and intraocular malignant melanoma. Study of two families and review of fortyfive cases. Cancer 1968; 21 : 119-25.

10 Shields JA, Augusburger JJ, Arbizo V, Morrison JF Jr, Lucier AC. Malignant melanoma of the choroid in a husband and wife. Br J Ophthalmol 1984; 68: 623-5.

11 Vogel F. Genetics of retinoblastoma. Hum Genet 1979; 52: 1-54.

12 Strong LC, Riccardi VM, Ferrell RE, Sparkes RS. Familial retinoblastoma and chromosome 13 deletion transmitted via an insertional translocation. Science 1981; 213: 1501-3.

Accepted for publication 15 May 1985. 